\title{
DISASTER MONITORING AND EMERGENCY RESPONSE SERVICES IN CHINA
}

\author{
Jianjun $\mathrm{Wu}^{1}$, Xingyi Han ${ }^{1}$, Yi Zhou ${ }^{2}$, Peng Yue ${ }^{3}$, Xiaoqing Wang ${ }^{4}$, Jingxuan $\mathrm{Lu}^{5}$, Weiguo Jiang ${ }^{1}$, Jing Li $^{1}$, Hong Tang ${ }^{1}$, Futao \\ Wang ${ }^{2}$, Xiaotao $\mathrm{Li}^{5}$, Jinlong Fan ${ }^{6}$ \\ 1. Faculty of Geographical Sciences, Beijing Normal University, Beijing, China (jjwu@ bnu.edu.cn) \\ 2. Institute of Remote Sensing and Digital Earth, Chinese Academy of Sciences (zhouyi@radi.ac.cn) \\ 3.Wuhan University (pyue@whu.edu.cn) \\ 4. Institute of Earthquake Forecasting, China Earthquake Administration (wangxiaoq517@163.com) \\ 5. China Institute of Water Resources and Hydropower Research (lujx@iwhr.com) \\ 6. National Satellite Meteorological Center, China Meteorological Administration (fanj1@cma.gov.cn)
}

\section{Commission III, ICWG III/Iva}

KEY WORDS: Emergency Response Service, Disasters, Satellite data, Earth Observations

\begin{abstract}
:
The Disaster Monitoring and Emergency Response Service(DIMERS) project was kicked off in 2017 in China, with the purpose to improve timely responsive service of the institutions involved in the management of natural disasters and man-made emergency situations with the timely and high-quality products derived from Space-based, Air-based and the in-situ Earth observation. The project team brought together a group of top universities and research institutions in the field of Earth observations as well as the operational institute in typical disaster services at national level. The project will bridge the scientific research and the response services of massive catastrophe in order to improve the emergency response capability of China and provide scientific and technological support for the implementation of the national emergency response strategy. In response to the call for proposal of "Earth Observation and Navigation" of 2017 National Key R\&D Program of China, Professor Wu Jianjun, the deputy chairman of Faculty of Geographical Science of Beijing Normal University, submitted the Disaster Monitoring and Emergency Response Service (DIMERS) project, jointly with the experts and scholars from Institute of Remote Sensing and Digital Earth, Chinese Academy of Sciences, Wuhan University, China Institute of Earthquake Forecasting of China Earthquake Administration and China Institute of Water Resources and Hydropower Science. After two round evaluations, the proposal was funded by Ministry of Science and Technology of China.
\end{abstract}

\section{BACKGROUND}

China is facing the increasing challenges from massive natural disasters at the background of the global warming, especially earthquake, typhoon, flood and drought, with serious casualties and losses. These natural disasters have their complex developing processes and mechanisms, of which may introduce severe secondary hazards. On the basis of scientific understanding the formation and evolution mechanism of disasters, the integrated development of monitoring, rapid assessing, emergency communicating and decision-making support technologies is the key to mitigate the serious natural disasters and ensure people's lives and property, as well as meet the high requirements for disaster monitoring and emergency response services.

Major developed countries in the world are actively improving and building application systems to deal with massive natural disasters. In China, remote sensing monitoring and assessment systems for massive natural disasters have also been successively developed. Compared with the leading international standards, the application of the key technologies of collaborative monitoring and assessment is slightly weak, and the capability of spatial information services and emergency response decision-making is not quite sufficient. Disaster emergency response of different type disaster and different stages is still lack of effective connection.
In response to the call for proposal of "Earth Observation and Navigation" of 2017 National Key R\&D Program of China, Professor Wu Jianjun, the deputy chairman of Faculty of Geographical Science of Beijing Normal University, submitted the Disaster Monitoring and Emergency Response Service (DIMERS) project, jointly with the experts and scholars from Institute of Remote Sensing and Digital Earth, Chinese Academy of Sciences, Wuhan University, China Institute of Earthquake Forecasting of China Earthquake Administration and China Institute of Water Resources and Hydropower Science. After two round evaluations, the proposal was funded by Ministry of Science and Technology of China.

\section{PROJECT OBJECTIVES}

The project will bridge the scientific research and the response services of massive catastrophe to improve the emergency response capability of China and provide scientific and technological support for the implementation of the national emergency response strategy. To be more specific:

-To improve the scientific understanding of the occurrence mechanism and evolution cycle of natural disasters through the technological integration of pilot tasks;

-To promote the development of emergency response service and decision-making technology to reduce the loss of the natural disasters; 
-To enhance the capacity of the national emergency response to natural disasters so as to ensure national emergency response with the scientific and technological support.

\section{RESEARCH AREA}

\subsection{China}

China is one of few countries in the world facing the most serious natural disasters with a high frequency of occurrence. The formation of natural disasters in China is deeply influenced by the natural environment and human activities, with obvious differences between the north and the south and between the east and the west of China.

China has complex geographical and climatic conditions. Almost all of the natural disasters happen in every year, such as floods, droughts, earthquakes, typhoons, wind and hail, snowstorms, landslides and debris flows, as well as the disasters caused by modern volcanic activities, pests and diseases, forest fires. The recent severe events are earthquakes in Yushu (2010), Lushan (2013), Dingxi (2013), Ludian (2014), and floods in Northeastern (2013), Boyang (2016), etc. Natural disasters in China show obvious regional characteristics, prominent seasonal and stage features, and symbiotic disasters and associated significant characteristics.

Natural disasters occur frequently in China, affecting more than 200 million people every year. In 1998, the direct economic loss of the China floods exceeded 300 billion RMB. In 2008, the Sichuan earthquake caused direct economic loss over 800 billion RMB. Natural disasters have become an important restricting factor for economic and social development.

\subsection{The Belt and Road Region}

The Silk Road Economic Belt and the 21st Century Maritime Silk Road, The Belt and Road (B \& R) for the short name, were approved by the central government of the People's Republic of China in 2013.The economic belt covers the historically related regions and countries of the Silk Road and Maritime Silk Road, including China, Central Asia, North and West Asia, the Indian Ocean coast and the Mediterranean coast.

The main areas of The Belt and Road are largely different in natural environment, diverse types of disasters. Heavy meteorological disasters and massive earthquakes have occurred several times in last century. In 2015, the 7.8 magnitude quake struck an area between the capital, Kathmandu, and the city of Pokhra, which 970 people had died in the quake, and that more than 1,700 had been injured. Also in the same year, severe flooding in Myanmar occurred in July and continued into September, affecting 12 of the country's 14 states, resulting in about 103 deaths and affecting up to one million people.

Most of the countries along The Belt and Road have weak capability in reduction and resilience to disasters. Natural disasters are the major threat to the development of most infrastructure projects and the sustainable development in the region. Although the number of deaths due to natural disasters has decreased in the past 30 years, the number of natural disasters has risen sharply. The increase in the total population living in areas prone to catastrophe has led to a substantial increase in economic losses year by year. From 1995 to 2015, among the top ten countries hit by meteorological disasters, seven countries along The Belt and Road were on the list. It can be seen that the countries along The Belt and Road are not only high in disaster risk but also in serious disaster losses area.

In the severe disaster situation, we need to continuously strengthen the support of science and technology in disaster reduction and resilience, promote the establishment of a coordinated and cooperative mechanism for regional cooperation and effectively fulfill our international obligations regarding disaster prevention and mitigation, so as to further support the international organizations in disaster prevention and mitigation in the Belt and Road Initiative.

\section{KEY COMPONENTS}

The DIMERS has chosen earthquake and secondary geological disasters and meteorological \& hydrological disasters as the major study target, will investigate the observation needs of space disaster monitoring and emergency response, and develop the key technology of disaster monitoring and emergency response based on demanding of disaster emergency response services.

Secondly, the project will integrate Earth observation data both at home and abroad based on the model method to carry out research on key technologies such as coordinated monitoring based on air and space, rapid assessment, dynamic decision, and building communications networks, and to form a model and a draft of related technical specifications for emergency response services of disaster coordination monitoring.

Thirdly, the key disaster management services based on the Beidou / wireless sensor networks integrated terminal and airspace disaster relief emergency communications system will be jointly utilized in the construction of mission-driven platform, to form the capabilities of data acquisition, rapid processing and information service;

Finally, The Belt and Road countries and regions will act as demonstration areas to provide pilot tasks, and providing advisory services to the State Council General Office, China International Rescue Team, Earthquake Relief Headquarters, Flood Control and Drought Relief Headquarters and the National Disaster Reduction Commission and other departments and agencies.

\subsection{Research \& Development}

The research of key technologies including four aspects:

- Resource Integrated Emergency Monitoring

- Rapid Assessment and Dynamic Decision

- Emergency Response Service

- Communication Networks.

\subsection{System of Systems}

To build the Platform of Emergency Response Service, including systems of:

- System of Earthquakes Monitoring and Assessment

- System of Landslides Monitoring and Assessment

- System of Floods Monitoring and Assessment

- System of Typhoons Monitoring and Assessment 


\subsection{Pilot Tasks}

To implement the case study on historical disasters and to carry out the response to the massive disasters that occurred during the implementation of the project:

- Emergency Response to Earthquakes in Gansu Province, China

- Emergency Response to Landslides in Sichuan Province, China

- Emergency Response to Floods in Huaihe River Basin, China

- Emergency Response to Drought in North China Plain

- Emergency Response to Natural disasters in "The Belt and Road Initiatives" Regions

\section{INTERNATIONAL COOPERATION}

For enhancing our capacity to conduct air-based and spacebased disasters monitoring for improved disaster emergency response service and promoting more countries benefited from this project, we are glad to share our experience and take sound advices from international community. DIMERS was present at the GEO WEEK 2017 Conference (Insight for a changing world, 23-27 October 2017, Washington, D.C., USA) to articulate its aiming to improve the capability of disaster reduction and resilience for the Belt and Road countries and regions; and DIMERS will also be an active contributor to the Developments, Technologies and Applications in Remote Sensing Conference (ISPRS) in May 7-10, 2018 Beijing, China.

DIMERS is keen to looking forward the international cooperation with related institute over the world, please contact us via the following address.

Address: No. 19, Xinjiekou Wai St., Haidian District, Beijing, P. R. China

Email: jjwu@ bnu.edu.cn

Phone: +86-01-5880 2283

\section{KEY PROJECT PARTNERS}

- Beijing Normal University

- Institute of Remote Sensing and Digital Earth, Chinese Academy of Sciences

- Wuhan University

- Institute of Earthquake Forecasting, China Earthquake Administration

- China Institute of Water Resources and Hydropower Research

- National Satellite Meteorological Center, China Meteorological Administration

- National Earthquake Response Support Service, China Earthquake Administration

- - Information Center, Ministry of Civil Affairs

- China Centre for Resources Satellite Data and Application

- Institute of Geology, China Earthquake Administration

- Taihu Basin Authority (TBA) of Ministry of Water Resources

- Capital Normal University

- SUN YAT-SEN University

- Lanzhou Institute of Seismology, China Earthquake Administration

- China Satellite Communications Co., Ltd

- Beijing Macro sense Information Technology Co., Ltd.

- Twenty First Century Aerospace Technology Co., Ltd.

\section{ACHNOWDGEMENTS}

This project is financially supported by the "Earth Observation and Navigation" of National Key R\&D Program of China with the grant number 2017YFB0504100. 